\title{
Influence of vegetable fibre (Abacá) in the construction process of cemented bases.
}

\author{
Gino Flor Chávez, Ing.Civil ${ }^{1}$, Jorge Arroyo Orozco, Ing.Civil ${ }^{2}$, and Ariana Aguilar Loaiza, Student of Ing. Civil ${ }^{3}$ \\ ${ }^{1}$ University of Guayaquil, Ecuador, ginoflorch@ug.edu.ec \\ ${ }^{2}$ University of Guayaquil, Ecuador, jorge.arroyoo@ug.edu.ec \\ ${ }^{3}$ University of Guayaquil, Ecuador, michellal_96@hotmail.com
}

\begin{abstract}
In recent years the influence of cemented bases in the construction of pavements in Ecuador has been indispensable in order to improve the mechanical strength of the structure and its physical properties. In this work, an evaluation will be carried out to assess the contribution of Abacá vegetable fibre in those bases to verify if the results are beneficial for the construction of pavements.

The research work is directly oriented to the study of the incorporation of a vegetable fibre of abaca to a granular base improved with cement. The length of the vegetable fibre plays an important role in the strength of the compound, which was verified that for a length of 20 and $25 \mathrm{~mm}$ a uniform mixture and greater adhesion in the particles of the soil, while an excessive length of the same, causes loss of the mechanical properties of the compound and difficulty in working.

The percentage of fibre attachment to the weight of the material was $0.5 \%$ and $1 \%$, for a percentage of $1 \%$ a decrease in resistance was found not meeting the minimum resistance required with the technical specifications. The incorporation of cement and fiber contribute to the carrying capacity of the soil but produces a loss of the resistance to bending and compression of the material.
\end{abstract}

Keywords-- quarry, Abaca, Vegetal fibre, cemented base, pavement.

\section{INTRODUCTION}

In 1917, the elaboration of cemented bases took place at the United States, with a mixture of soil cement which they called "soilamies", with the contribution of the PCA (Portland Cement Association) in the 1930's and 1940, was developed the stabilization with soil-cement in a quite efficiently and safely way. In 1938, at the state of California, the cemented base started building the first road in certain traffic conditions, being a reference to be implemented in other states and countries.

The cemented bases provide support to the pavement's structure, since the base is the responsible layer of receiving the most amount of effort produced by the traffic, increasing the service life of the structure. In general terms, a stabilized base

Digital Object Identifier (DOI):

http://dx.doi.org/10.18687/LACCEI2020.1.1.236

ISBN: 978-958-52071-4-1 ISSN: 2414-6390 modifies the way in which a pavement responds to the exerted loads, that's why the pavements that have a stabilized base in their structure are called semi-rigid pavements, because of their strength, the stabilized base tends to behave as similar as a concrete slab.

In this work, we will verify how useful can be the fiber implement in a cemented base, for which the investigation started with a 1B type base material according to its grain size and the MTOP[6] specifications, in addition the optimal percentage of the cement use was chosen, and was in the range of $3 \%$ to $5 \%$ depending on the material, for which a sample of 39 specimens (30 cylinders and 9 beams) was made to determine the compression and bending strength with the specifications of the ASTM standards [ C39 and ASTM C78, checking the specimens for breakage at 7,14 and 28 days respectively.

\section{CEMENT BASES}

To prepare the cemented bases, the material of the 1 Type Base was extracted from the PROGECON quarry, located in Via a Daule-Guayaquil-Ecuador. The abaca's vegetable fibre and the chemical binder to be used will be a $\mathrm{MH}$ cement type of moderate hydration heat provided by the HOLCIM S.A. (S.A) [8] Company. Referring to the abaca's fibre, was obtained from the stem of the same tree, its production is obtained from 18 to 24 months in tropical climates whose temperature range from $22^{\circ}$ a $28^{\circ} \mathrm{C}$ with one harvest every two and three months. These fibers are salt water resistant and absorb high amounts of water.[7]

The construction process of a base stabilized with cement is adapted according to the requirements in the field of civil engineering.

1. Homogenize the material when is used so that everything has the same moisture by spreading the sample for 24 hours in a natural state environment.

2. Select the percentage of chemical binder (cement) to be used according to the type of material.

3. Select the water dose according to the test carried out on the material using the Modified Proctor test (ASTM D - 1557).

4. Moisten the material with water and cement until a uniform mixture is obtained. 
5. Make 4 layers in the cylindrical mould, compacting with a vibrating hammer for 20 seconds per layer.

6. Then proceed to seal and wait 24 hours to demould and cover the cylinder with a sheath to maintain its moisture.

7. Prepare the sample breakages to be tested, on their respective days at 7,14 and 28 days.

In the cemented bases with fiber, the same process will be performed but adding a fiber percentage of $0,5 \%$ and $1 \%$ weight of the total sample of each specimen to be tested.

The loads applied for the stress tests are in tonnes at the centre of the cylindrical specimen. (See Figure 1).

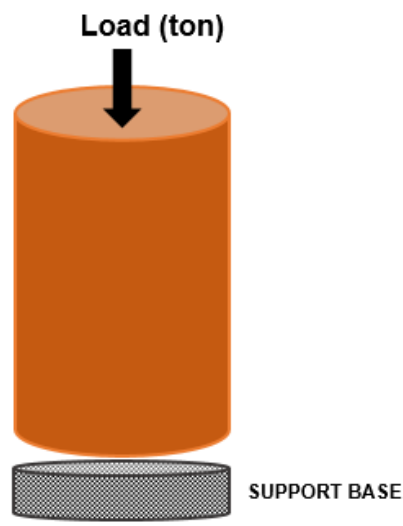

CEMENTED. Application of point load in tons.

Figure 1.Load Application for Cemented Base (Cylinder) Source: Own

\section{BEAMS (RESISTANCE TO BENDING)}

Eight beams are produced to calculate the break module and to make a comparison between a cement-based beam and additional fiber complying with ASTM C78 norms (-ASTM), which indicates that the load is applied to each third of the light distributed by applying it in proportion to half load. (See Figure 2).

The break module is lower in the case of the load at the midpoint and the maximum voltage in the middle third of the beam.

The beam break module is calculated by this way:

- If the fracture starts on the tension surface, within the middle third of the length between supports, calculate the rupture module as follows:

$$
R=\frac{P L}{b d^{2}}
$$

$\mathrm{R}=$ Rupture Module (psi or Mpa)

$\mathrm{P}=$ Maximum applied load, indicated by the machine (lbf or $\mathrm{N}$ )

$\mathrm{L}=$ Length between supports, (in. or $\mathrm{mm}$ )

$\mathrm{b}=$ Average width of specimen (in. or $\mathrm{mm}$ ), in the fracture.

$\mathrm{d}=$ Average height of specimen (in. or $\mathrm{mm}$ ), at fracture.

Note 1: Beam weight is not included in the calculation.

- If the fracture occurs on the surface at tension out of the middle third of the length between supports, but at a distance not greater than 5\% free light, calculate the break module as follows:

$$
R=\frac{3 P a}{b d^{2}}
$$

Where:

$\mathrm{a}=$ Average distance between the fracture line and the nearest support, measured on the tensile surface (in. or $\mathrm{mm}$ ).

Note 2: Beam weight is not included in the calculation.

- If the fracture occurs on the surface at tension out of the middle third of the length between supports, for more than $5 \%$ of the free light, discard the test result.

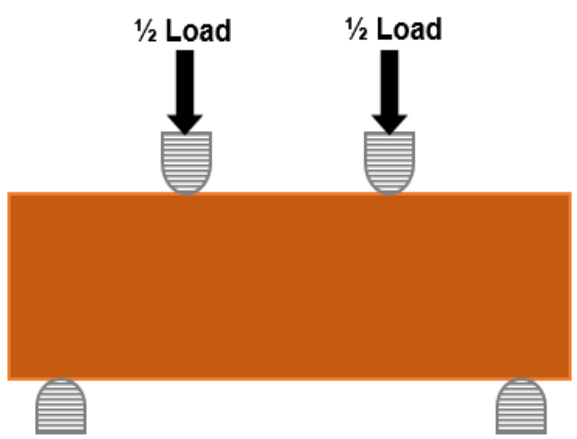

ASTM C78. Loads at the third points. Half of the load is applied in each third of the light. The break module is lower than in the case of the load at the midpoint. The maximum voltage in the middle third of the beam.

Figura 2.Loading application for beams. Source: Own

\section{MODIFIED PROCTOR TEST}

It is made according to the ASTM D-1557 standard (See table 1), its objective is to determine the optimum moisture content to compact a soil and obtain the maximum density. It is done according to the requirement to use, for road projects Proctor Modified is always chosen because the compacting energy is much higher, it should be noted that it is an empirical analysis but from this test it is possible to have a panorama for the compaction of a soil. [2]

Where: 
Table 1. Methods for performing the Modified Proctor Test.

\begin{tabular}{|c|c|c|c|}
\hline \multicolumn{4}{|c|}{ MODIFIED PROCTOR TEST ASTM D-1557 } \\
\hline \multirow{3}{*}{\begin{tabular}{|l|} 
Hammer \\
Height of drop \\
\end{tabular}} & \multicolumn{3}{|c|}{$10 \mathrm{lb}}$. \\
\hline & \multicolumn{3}{|c|}{18 in. } \\
\hline & Method A & Method B & Method C \\
\hline Material & $\begin{array}{l}\text { Sieve pass } \\
\text { No.4 }\end{array}$ & $\begin{array}{c}\text { Sieve pass } \\
3 / 8^{\prime \prime}\end{array}$ & $\begin{array}{c}\text { Sieve pass } \\
\text { 3/4" }\end{array}$ \\
\hline $\begin{array}{l}\text { Minimum } \\
\text { amount of dry } \\
\text { mass. }\end{array}$ & $16 \mathrm{~kg}$ & $16 \mathrm{~kg}$ & $29 \mathrm{~kg}$ \\
\hline $\begin{array}{l}\text { Minimum } \\
\text { amount of } \\
\text { moisture mass }\end{array}$ & $23 \mathrm{~kg}$ & $23 \mathrm{~kg}$ & $45 \mathrm{~kg}$ \\
\hline Mould & 4" & 4" & 6" \\
\hline No. of layers & 5 & 5 & 5 \\
\hline $\begin{array}{l}\text { No. of Blows per } \\
\text { layer }\end{array}$ & 25 & 25 & 56 \\
\hline $\begin{array}{l}\text { Mould volume } \\
\text { (without collar) }\end{array}$ & $944 \mathrm{~cm} 3$ & $944 \mathrm{~cm} 3$ & $2123 \mathrm{~cm} 3$ \\
\hline $\begin{array}{c}\text { Compacting } \\
\text { energy }\end{array}$ & $\begin{array}{c}2700 \\
\mathrm{KN}-\mathrm{m} / \mathrm{m} 3\end{array}$ & $\begin{array}{c}2700 \\
\mathrm{KN}-\mathrm{m} / \mathrm{m} 3\end{array}$ & $\begin{array}{c}2700 \\
\mathrm{KN}-\mathrm{m} / \mathrm{m} 3\end{array}$ \\
\hline
\end{tabular}

Source: American Society for Testing and Materials o ASTM International

For the research was conducted the Proctor Modified test for the base material, additional for the material with $4 \%$ cement because it was the optimal percentage, and at the same percentage was added fiber to the $0.5 \%$ that was proven as the best alternative, so with these results to determine the optimum moisture content of the sample. The water content to use was $400 \mathrm{gr}$ in Natural state, $600 \mathrm{gr}$ for the combination plus fiber and cement and 500 gr for the soil cement.

Because fibre absorbs more water, they have higher density than granular bases but lower than cemented bases.

\section{CBR (CALIFornia BEaring Ratio)}

The C.B.R. is the Index of California or Bearing Capacity of California (California Bearing Radio). It is a measure of resistance of a soil to shear effort under conditions of density and humidity. The C.B.R. test is performed on altered, unchanged or compacted samples, saturated or not; or on the ground, expressed as a percentage (\%) and determine the optimum humidity in order to obtain the maximum dry density. Based on the Modified Proctor assays, we analyze the CBR assay, for the soil in its natural state, the soil with cement and soil with cement plus fiber.

\section{METHOD}

Various laboratory tests will be carried out to achieve the characterization of the material to be used (See Table 2) and to verify its base type (See Figure 3), based on the results, the specimens are made using a curing process for the Abaca plant fibre, which consists of immersing it in water for 24 hours in order to saturate it (See figure 4).

Taking into account that the existing properties of the fiber are not altered or modified in the process. Water, in turn, plays a vital role in the elaboration of the specimens, since it is the case that an excess of water is implemented, the sample is saturated and the resistance to it is lost, therefore all the tests necessary prior to the hydration of the mixture have been carried out.

According to Table 2 it is noted that it meets most of the requirements except for the CBR Index which does not reach the minimum value required by the specification, which is why it is added chemical binder (cement HOLCIM BASE ROAD) to know the mechanical properties of the material. [7]

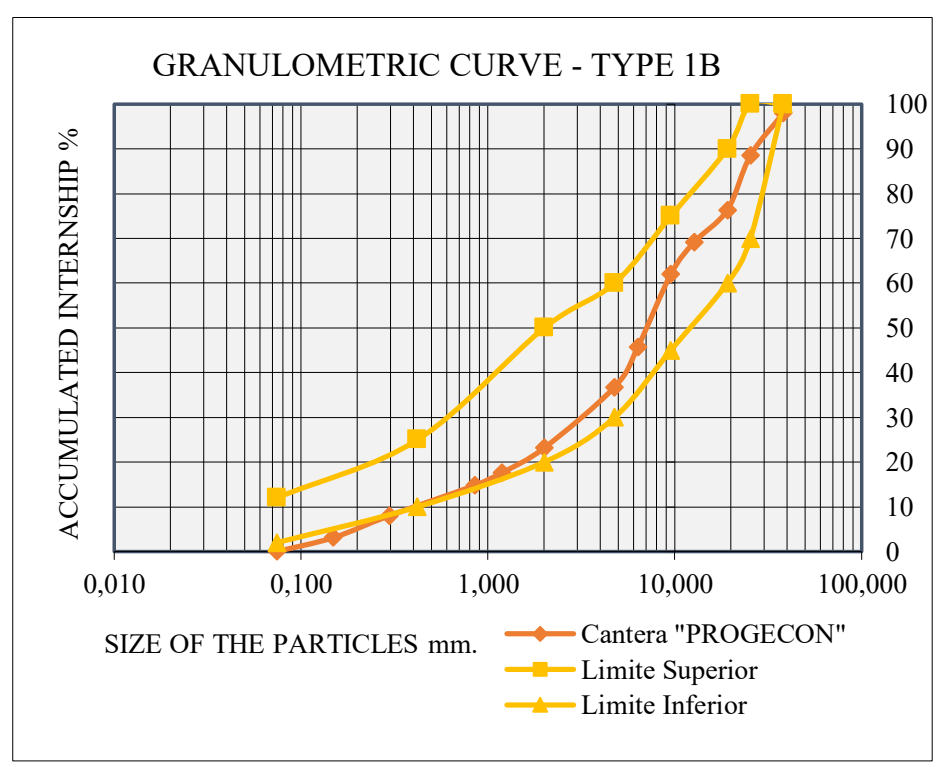

Figure 3. Particle size limits according to the MTOP. Source: Own

Table 2.Material Characterization

\begin{tabular}{|l|c|}
\hline \multicolumn{1}{|c|}{ BASE TYPE 1B } & RESULTS \\
\hline $\begin{array}{l}\text { Classification according to } \\
\text { SUCS }\end{array}$ & $\begin{array}{c}\text { GRAVEL WELL } \\
\text { GRADUATED }\end{array}$ \\
\hline Plasticity Index & NP \\
\hline Limit Liquid & - \\
\hline Sulfate Wear & $3,45 \%$ \\
\hline Abrasion of Angels & $28,50 \%$ \\
\hline CBR Index & $35 \%$ \\
\hline \multicolumn{2}{|c|}{ Source: Own }
\end{tabular}




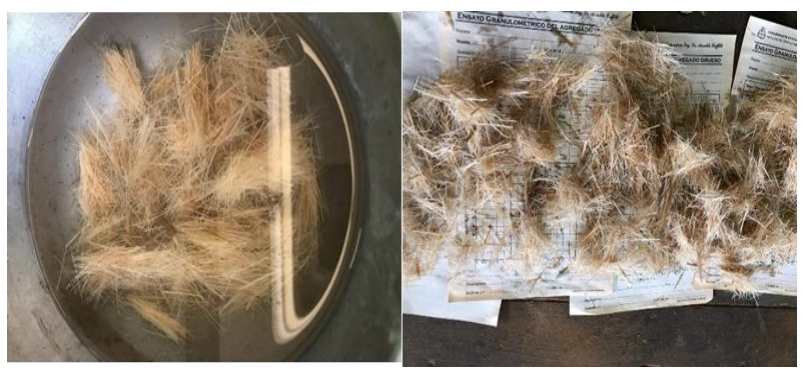

Figure 4. Saturation of Abaca vegetable fibre. Source: (Jurado Nohelia, Abril,2019)

Specimens shall be prepared using the above process. The idea of adding abaca vegetable fiber refers to several studies carried out on concrete beams with fibers where the increase in bending resistance could be noticed.[7], another example is an improvement of a clay soil that was added fibers made the deformations smaller and generated stability with workable sizes of 15 to $20 \mathrm{~mm}$. [5]

The majority of the reinforced compounds achieve a better resistance to fatigue, greater rigidity and a better resistance ratio \# weight. For this, the proper selection of the type, quantity and orientation of the fiber is very important when it comes to forming a material because it has a direct relationship with the material of the matrix that transmits the force to the fibres, which support most of the force.

The presentation or configuration of fibres (short, long, woven and other) are responsible for conferring important mechanical properties on the material (high specific tensile strength and high specific modulus). In addition to other characteristics such as lightness, thermal resistance, compactness with resins, hardness, rigidity and adaptability to the manufacturing process. [7]

The cement to be used will be a Road Base Cement (Type MH) of low hydration heat, which is developed to obtain adequate resistances that allow to improve and stabilize the soil, In addition, they generate a reduction in the cost of preparing healers of the thickness of the floors.

According to studies conducted by HOLCIM S.A and the American Concrete Institute (ACI) committee, it recommends minimum percentages required according to the AASTHO soil classification, below (See Table 3).

The percentages will be in the range of 3\% to $5 \%$ with respect to the classification of the material (WELL GRADUATED GRAVEL-GW).
Table 3.Typical requirements for cement according to the type of soil.

\begin{tabular}{|c|c|c|}
\hline $\begin{array}{c}\text { AASHTO SOIL } \\
\text { CLASSIFICATI } \\
\text { ON. }\end{array}$ & $\begin{array}{c}\text { ASTM } \\
\text { CLASSIFICATIO } \\
\text { N OF SOIL. }\end{array}$ & $\begin{array}{c}\text { TYPICAL RANGES OF } \\
\text { THE REQUIRED } \\
\text { CEMENT WEIGHT, \% }\end{array}$ \\
\hline A-1-a & $\begin{array}{c}\text { GW,GP,GM,SW, } \\
\text { SP,SM }\end{array}$ & $3-5$ \\
\hline A-1-b & GM,GP,SM,SP & $5-8$ \\
\hline A-2 & GM,GC,SM,SC & $5-9$ \\
\hline A-3 & SP & $7-11$ \\
\hline A-4 & CL,ML & $7-12$ \\
\hline A-5 & ML,MH,CH & $8-13$ \\
\hline A-6 & CL,CH & $9-15$ \\
\hline A-7 & MH,CH & $10-16$ \\
\hline
\end{tabular}

Source: Report of the committee ACI

\section{ANALYSIS OF THE RESULTS}

Please note that the basic material extracted from quarry does not generally meet the specifications of the MOP (Ministry of Public Works, which is why material improvement is carried out by increasing a small percentage of cement according to the requirement, to meet these requirements and to improve the bearing capacity of the soil.

For this purpose, tests were carried out with different percentages of cements according to the type of soil classification to determine the optimal percentage of agglomerate.

The percentages of cement added were 3, 4 and $5 \%$ where an increase in compression resistance was observed at 7, 14 and 28 days. In addition, the cores with 4 and 5\% cement show greater resistance with nearby values. It was decided to work with a cement percentage of $4 \%$ because it had similar resistances and in order to make it economically viable it was the optimal value. (See Figure 5).

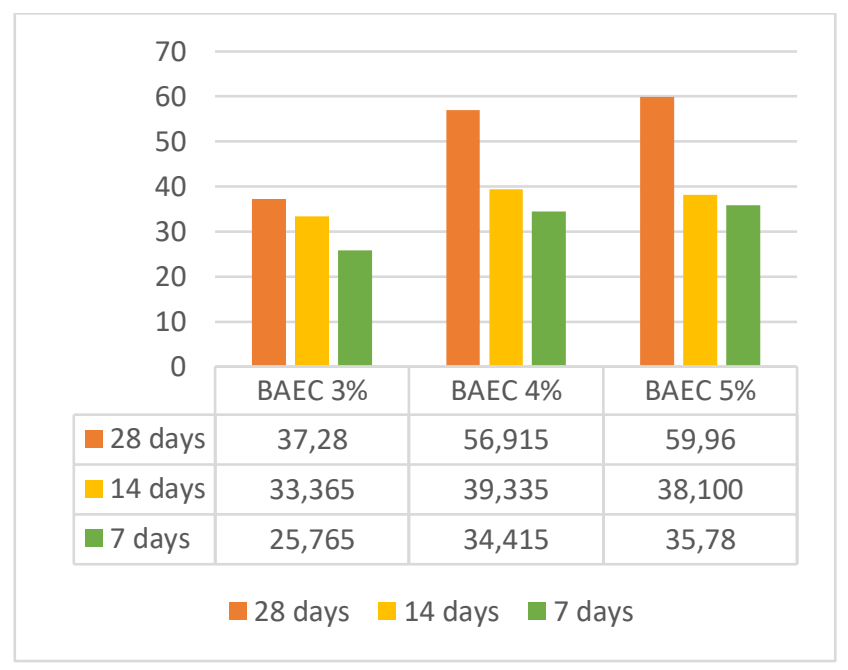

Figure 5.The percentages of cement Source: Own 
Once obtained the optimal percentage of cement, specimens were made with different percentages of vegetable fiber, 0.5 and $1 \%$ respectively were obtained decreases in resistance with both percentages of fibres compared to the bases stabilized with only cement, and presenting greater conflict with specimens made with a percentage of $1 \%$, due to their difficulty in achieving homogenization of the sample and achieving a uniform specimen.

The compressive strength of the specimens made with $0.5 \%$ showed greater compressive strength in relation to those of $1 \%$. Its increase was about $40 \%$ at 28 days where the maximum resistance of the materials is reached. (See Figure 6 and 7).

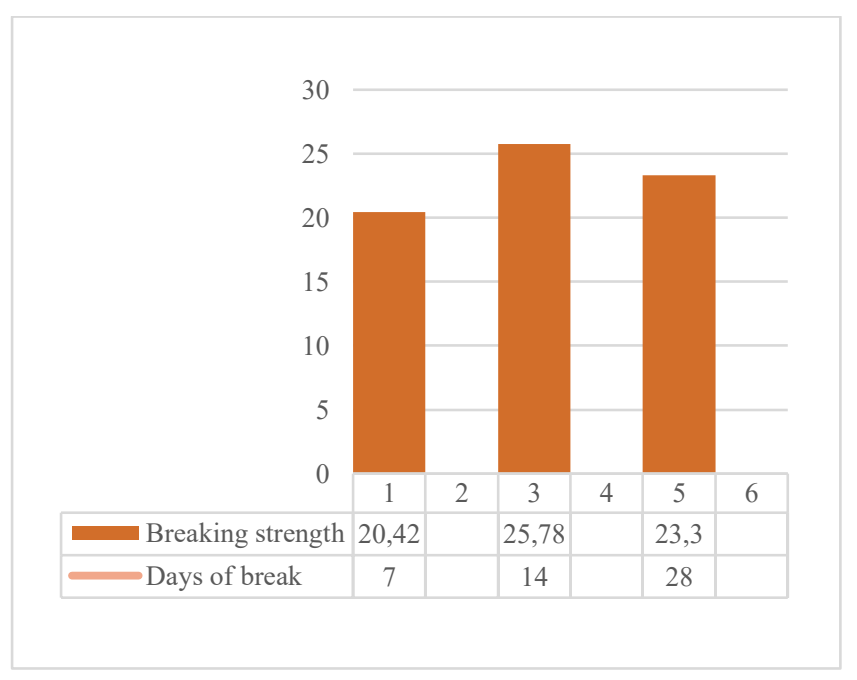

Figure 6. Cemented base 4\% cement and $1 \%$ fiber. Source: Own

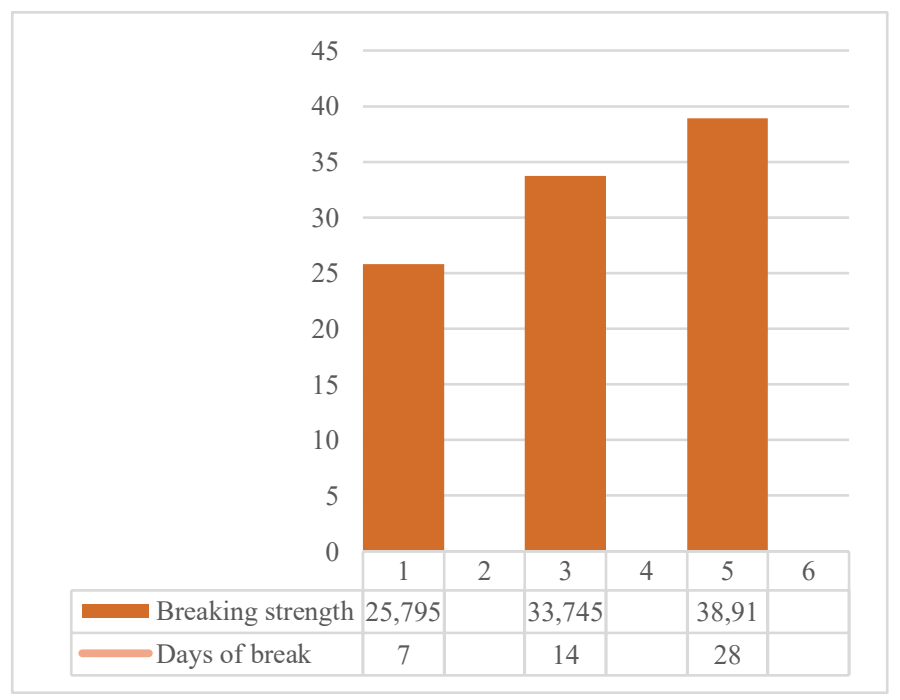

Figure 7. Cemented base 4\% cement and 0, $5 \%$ fiber. Source: Own

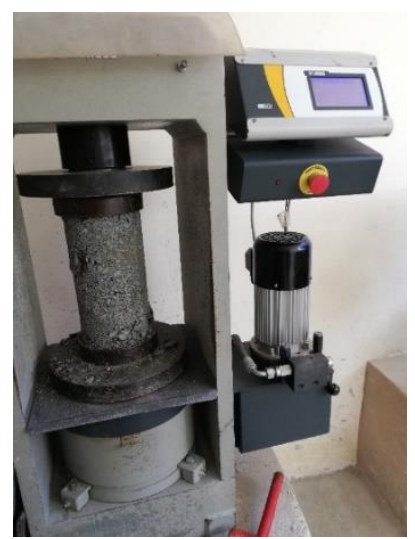

Figura 3. Specimen test machine - Compression resistance Source: Own

With the samples (beams) produced for the bending test the following results were obtained: the beams with $4 \%$ cement act bearing more load when starting the break of the specimen in relation to the beams with presence of fiber, which fail, but his fracture is not performed. The difference between the increments is very small in the beam that has $1 \%$ of fiber in relation to that of $0.5 \%$ but, however, they decrease by $30 \%$ with respect to the result obtained with beams with only granular material and cement. (See Figures 8).

The machine that performs the bending resistance test, implements load in Newton (N) to produce the break, and the break module is calculated as follows: (See table 4).

Table 4.Breaking Load (N)

\begin{tabular}{|c|c|}
\hline Breaking load(N) & $\begin{array}{c}\text { Breakout Module } \\
\text { (MPa) }\end{array}$ \\
\hline \multicolumn{2}{|c|}{ 4\% Cement + 0,5 Fibre } \\
\hline 11550 & 1,64 \\
\hline 12354 & 1,76 \\
\hline 15933 & 2,27 \\
\hline \multicolumn{2}{|c|}{ 4\% Cement + 1 Fibre } \\
\hline 9862 & 1,40 \\
\hline 11342 & 1,61 \\
\hline 12132 & 1,73 \\
\hline \multicolumn{2}{|c|}{ 4\% Cement } \\
\hline 10753 & 1,53 \\
\hline 15678 & 2,23 \\
\hline 17488 & 2,49 \\
\hline
\end{tabular}

Source: Own 


\section{CALCULATION OF THE RUPTURE MODULE:}

The fracture occurs within the middle third, so the equation is used (1).

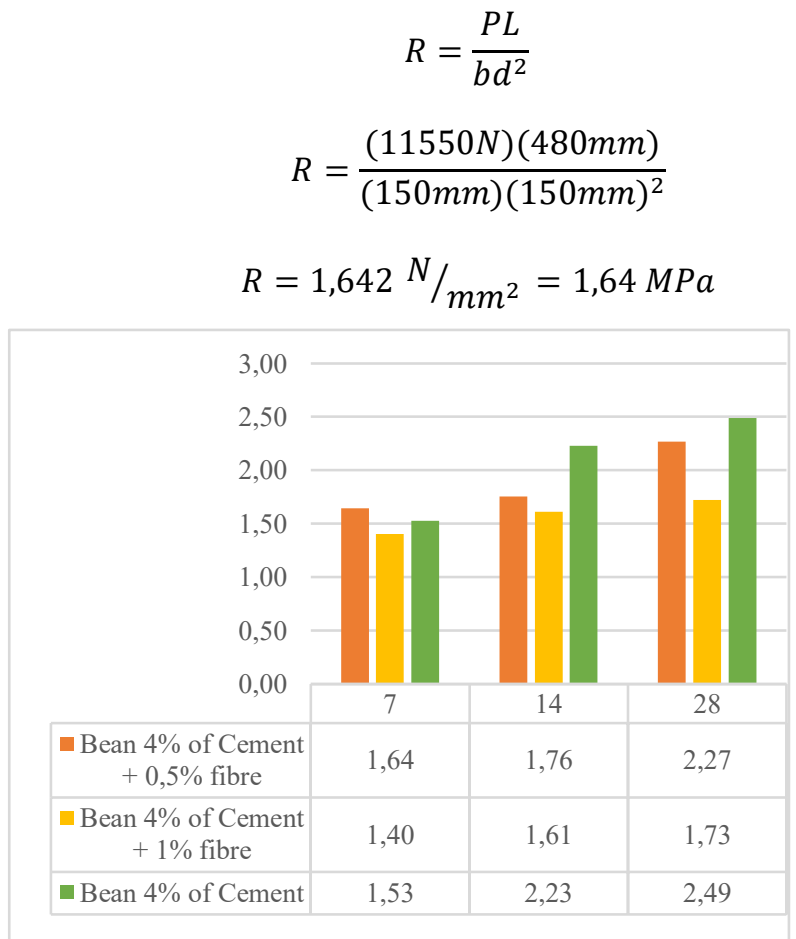

Figure 8.Bending resistance at 7-14-28 days.

Source: Own

The tests performed by Proctor Modified and CBR, when performing the test for the combination of material plus cement and fiber the amount of water increased 200 gr, because the fiber absorbs water to the compound, a density of $2064 \mathrm{~kg} / \mathrm{cm} 3$ and an optimal moisture content of $8.40 \%$ was obtained for the soil cement + fibre, a density of $2233 \mathrm{~kg} / \mathrm{cm} 3$ and an optimal humidity of $7.81 \%$ was obtained for the soil and CBR tests, For the cement floor the material was with a CBR rate of $85 \%$ and for the cement floor more fibres $131 \%$, and the soil in the natural state had a CBR of 35\%. (See Figure 9, 10 and 11). [5]

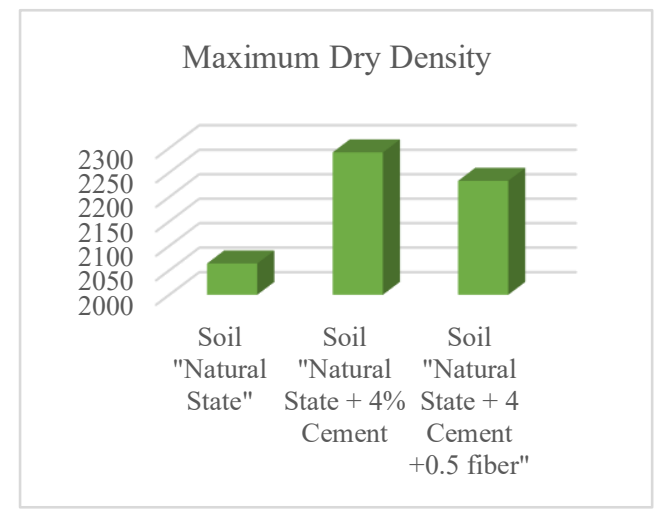

Figure 9.Maximum Dry Densities
Source: Own

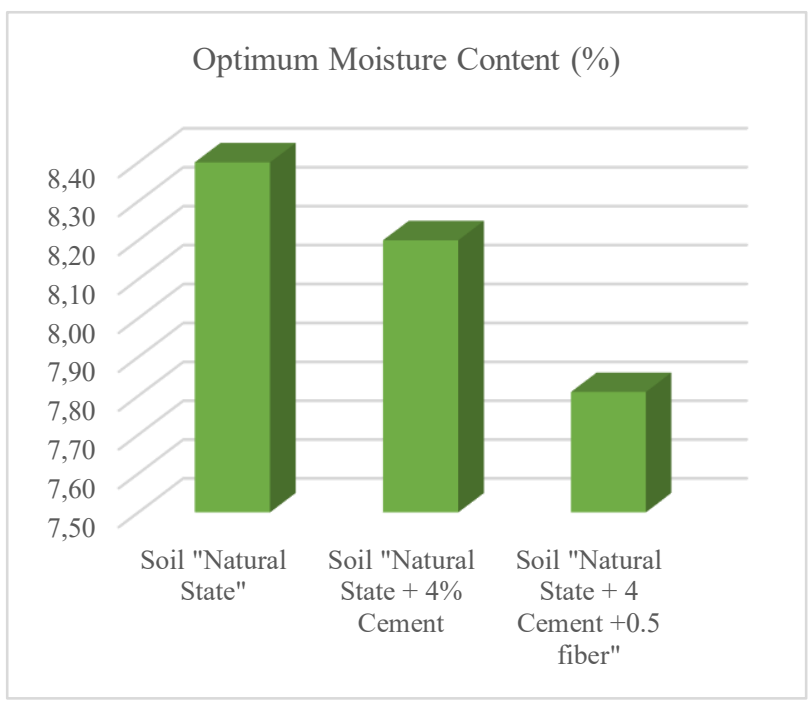

Figure 10.Moisture Contents Source: Own

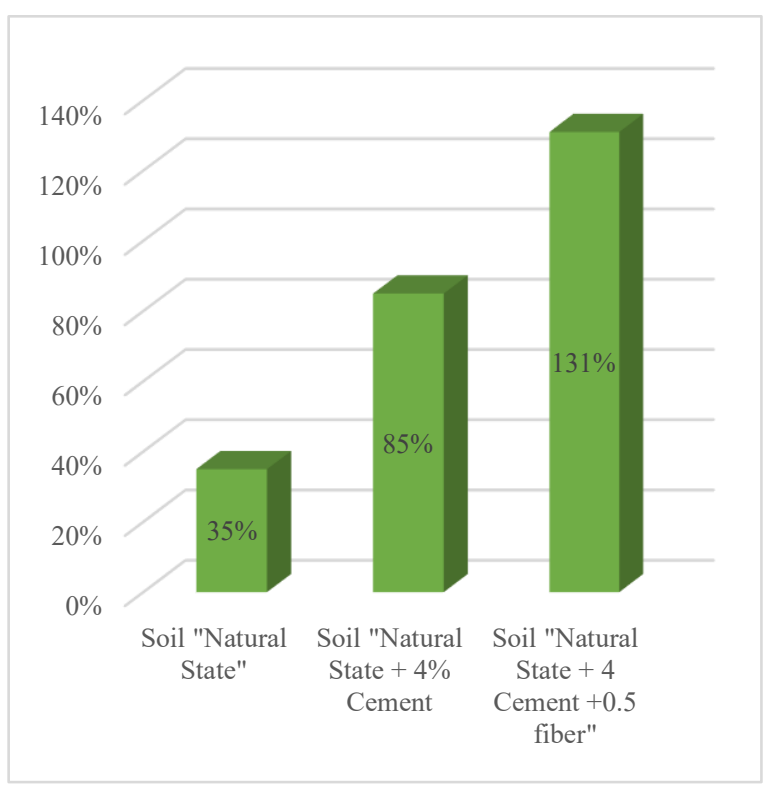

Figure 11.CBR

Source: Own 


\section{CONCLuSIONS}

- The material procorcionated as Granular Base type 1B did not meet the requirements of the standard used.

- A study was carried out of a stabilized with 3,4 and $5 \%$ of cement found that at higher quantity of cement we can obtain better bearing capcity.

- It was found that the optimum percentage of abaca fibre was $0.5 \%$ with respect to the weight of the cement because higher percentages make it impossible to make test pieces.

- The increase in resistance in the spikes tested with the different percentages of cement is much greater in comparison with the values obtained by addicting fibres.

- The addition of fiber in the base stabilized with cement helped the test tubes not to break, as the fiber holds the material together even after reaching its maximum load, providing adhesion to the matrix of the material maintaining its shape by having joined the particles of the soil.

- In addition, the percentage of $1 \%$ of fibre to the compound reduces by $20 \%$ the resistance due to an excessive use of material, and if a proper distribution of the same directly affects its composition.

- The results obtained cannot ensure that the cement and the vegetable fibre can be used to increase the life of a pavement, because the tests carried out managed to reduce its resistance.

\section{RECOMMENDATIONS}

- Carry out a uniform distribution in the BASE+ CEMENT mixture to achieve the maximum strength.

- Apply the same compacting energy to the 4 layers with the vibrating hammer.

- Keep the specimen moist until breakages are performed and failure models are verified.

- Perform a curing to the vegetable fiber, managing to keep its physical and chemical properties.

- Continue the studies of abaca fibers to know the durability in cemented bases.

\section{REFERENCES}

[1] América, J. J. (2013). Bases con Agregados de Cemento de tres minas ( Quito). Quito.

[2] -ASTM, A. S. (s.f.). NORMAS ASTM. Estados Unidos.

[3] Jurado Nohelia, C. V. (Abril,2019). Evaluación de la aplicación de un aglomerante químico y fibra vegetal para el mejoramiento de la subrasante de las vías en el sector zapotal nuevo, cantón ventanas-provincia de los ríos. Guayaquil.

[4] Luzuriaga, J. (2017). Composite de matriz de cemento y refuerzo de Abacá. Loja.

[5] Moscoso, J. C. (2002). Refuerzos con fibra de Abacá - Tesis. Quito.

[6] Republica del Ecuador, M. d.-M.-0.-F.-2. (2002). Especificaciones Generales para la cobstruccion de Caminos y Puentes . Quito.

[7] Rocci. (1964). BASES CEMENTADAS .

[8] S.A, H. (s.f.). Cemento Base Vial MH. 20. 